\title{
Comparison of the 8th union for international cancer control lymph node staging system for gastric cancer with two other lymph node staging systems
}

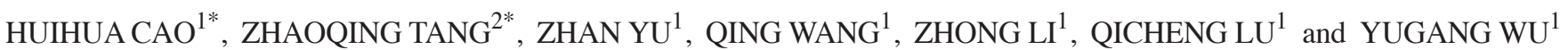 \\ ${ }^{1}$ Department of General Surgery, The Third Affiliated Hospital of Soochow University \\ (The First People's Hospital of Changzhou), Changzhou, Jiangsu 213000; ${ }^{2}$ Department of General Surgery, \\ Zhongshan Hospital, Fudan University, Shanghai 200032, P.R. China
}

Received March 13, 2018; Accepted October 4, 2018

DOI: $10.3892 / \mathrm{ol} .2018 .9694$

\begin{abstract}
The log odds of positive lymph nodes (LODDS) and the metastatic lymph node ratio (MLR) staging systems have previously been demonstrated to exhibit advantages compared with the tumor-node-metastasis (TNM) staging system in predicting the prognosis of gastric cancer. The current study compared the prognostic significance of the newest Union for International Cancer Control Node classification with the LODDS and MLR staging systems. From September 2010 to December 2012, all medical records for patients with gastric cancer at the Third Affiliated Hospital of Soochow University were retrospectively analyzed and the clinicopathologic characteristics were reviewed. Cut-off points were selected to divide the patients with gastric cancer into different groups. Univariate and multivariate analyses were performed to identify the prognostic risk factors for gastric cancer. The Harrell's concordance index (C-index) was adopted to compare the prognostic value of the three staging systems. A total of 877 patients with gastric cancer who met the inclusion criteria were analyzed in the current study. The patients were classified according to the three MLR subgroups as follows: MLR0 $(\mathrm{MLR}=0), \mathrm{MLR} 1(0<\mathrm{MLR} \leq 0.28)$ and MLR2 $(0.28<\mathrm{MLR}<1)$. The patients were classified according to the LODDS subgroups as follows: LODDS1 (LODDS $\leq-0.5)$, LODDS2 $(-0.5<\mathrm{LODDS} \leq 0), \mathrm{LODDS} 3(0<\mathrm{LODDS} \leq 0.5)$ and LODDS 4 (LODDS $>0.5$ ). Based on multivariate analysis, LODDS, MLR and pathological node $(\mathrm{pN})$ stage could significantly predict
\end{abstract}

Correspondence to: Dr Yugang Wu, Department of General Surgery, The Third Affiliated Hospital of Soochow University (The First People's Hospital of Changzhou), 185 Juqian Street, Changzhou, Jiangsu 213000, P.R. China

E-mail: czyywyg89@163.com

${ }^{*}$ Contributed equally

Key words: gastric cancer, metastatic lymph node ratio, log odds of positive lymph nodes, prognosis, staging system survival rates of patients with gastric cancer. According to the $\mathrm{C}$-index, the LODDS staging system more accurately predicted the 5-year overall survival for patients with gastric cancer compared with the other two staging systems. In summary, the current study has identified that LODDS may be superior to the MLR and $\mathrm{pN}$ staging systems in predicting the prognosis of patients with gastric cancer. However MLR may exhibit advantages compared with LODDS for patients who have undergone adequate lymphadenectomies.

\section{Introduction}

Gastric cancer is the fourth most common cancer type worldwide, with $>93,000$ new cases diagnosed every year, and is the second leading cause of cancer-associated cases of mortality, following lung cancer with 700,000 deaths each year $(1,2)$. Gastric cancer is considered to be prevalent in east Asia, particularly in China (3). Currently, primary tumor resection with lymphadenectomy is the main surgical treatment for resectable gastric cancer; however, most cases of gastric cancer are diagnosed in the advanced stage as the symptoms of early stage disease are often atypical (4).

The 8 th edition of the tumor-node-metastasis (TNM) staging system (5), established by the American Joint Committee on Cancer and the Union for International Cancer Control (UICC), is the most commonly used system for predicting the prognosis of gastric cancer (6). The 8th edition TNM staging system is considered to be an objective and reliable method for predicting the prognosis of patients with gastric cancer (7), however, the requirement of at least 15 retrieved lymph nodes (LNs) limits the use of this system in clinical practice (8). Furthermore, stage migration may occur if a low number of LNs are retrieved, which may underestimate the severity of the disease (9).

Previously, a number of new methods for predicting the prognosis of gastric cancer have been proposed. The metastatic lymph node ratio (MLR) is used as a supplement to the TNM staging system and is defined as the ratio of metastatic LNs to the total number of retrieved LNs (10). Several previous studies have demonstrated that MLR has advantages compared with the UICC pathological node $(\mathrm{pN})$ staging system in predicting 
the prognosis of gastric cancer (11-14). Another prognostic parameter, the log odds of positive LNs (LODDS), is defined as the log of the ratio of positive LNs to negative LNs (15). A number of studies have indicated that the prognostic value of LODDS is superior to the MLR and pN systems (15-17). The current study evaluated the prognostic significance of the LODDS and MLR staging systems compared with the 8th UICC pN staging system.

\section{Materials and methods}

Patients. Between September 2010 and December 2012, all medical records for patients with gastric cancer treated at the Third Affiliated Hospital of Soochow University (Changzhou, China) were retrospectively analyzed. The inclusion criterion was adenocarcinoma R0 resection with D2 LN dissection. Patients with M0 and M1 statuses were excluded from the study. Patients who had received neoadjuvant chemotherapy or radiotherapy were also excluded due to the possibility of incorrect staging. Specific data are presented in Fig. 1. Clinicopathologic characteristics, including age, sex, tumor size, tumor location, tumor differentiation, tumor depth (pT stage), pN stage and TNM stage, were reviewed. Follow-up was conducted by telephone calls, e-mails and on-site visits. Informed written consent was received from all patients and the current study was approved by the Ethics Committee of The Third Affiliated Hospital of Soochow University.

Different LN categories. All included patients were staged using the 8 th edition of the TNM staging system. The $\mathrm{pN}$ stage classification was performed as follows: N0, negative; N1, 1-2 positive LNs; N2 , 3-6 positive LNs; N3a, 7-15 positive LNs; and $\mathrm{N} 3 \mathrm{~b}>15$ positive LNs. Negative was used to mean no lymph node metastasis, while positive was used to mean lymph node metastasis. MLR was calculated as follows: MLR=metastatic LNs/retrieved LNs. The median MLR was selected as the cut-off value to divide the patients into three subgroups. The median MLR was 0.28 , therefore the patients were classified into three subgroups as follows: MLR0 (MLR=0), MLR1 $(0<\mathrm{MLR} \leq 0.28)$ and MLR2 $(0.28<\mathrm{MLR}<1)$. LODDS was calculated as follows: $\operatorname{LODDS}=\log (\operatorname{pnod}+0.5) /(\operatorname{nnod}+0.5)$, where pnod is the number of positive LNs and nnod is the number of negative LNs. The LODDS cut-off value was determined by comparing the 5 -year overall survival rate with an interval of 0.5. As presented in Table I, patients were classified into four subgroups based on their LODDS value, as follows: LODDS1 (LODDS $\leq-0.5)$, LODDS2 $(-0.5<$ LODDS $\leq 0)$, LODDS3 $(0<$ LODDS $\leq 0.5)$ and LODDS4 (LODDS $>0.5)$.

Statistical analysis. All analyses were performed using SPSS (version 16.0; SPSS, Inc., Chicago, IL, USA) and R software (version 3.0.0; www.r-project.org). Kaplan-Meier analysis followed by a log-rank test was used to compare the survival between subgroups. Univariate and multivariate analyses were performed using a Cox proportional hazards model. The Harrell's concordance index (C-index) was used to compare the accuracy of the prognostic predictions of different staging systems. A higher C-index indicates a better predictive accuracy. $\mathrm{P}<0.05$ was considered to indicate a statistically significant difference.

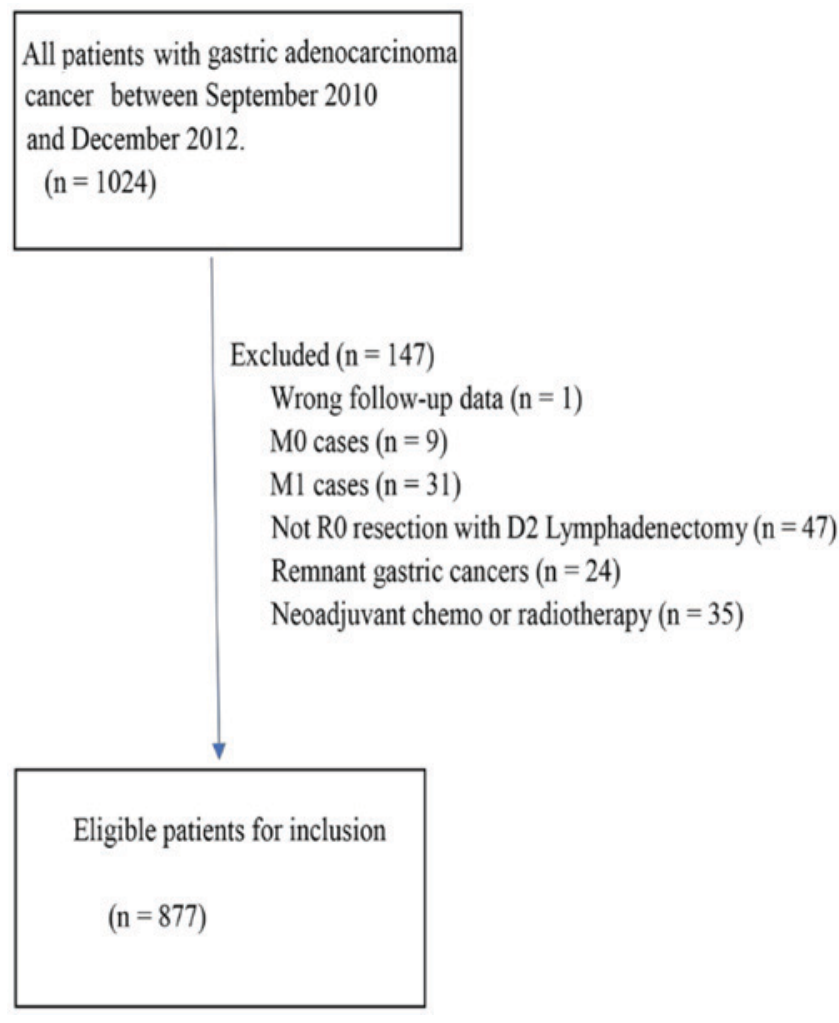

Figure 1. Inclusion criteria of the current study.

\section{Results}

Patient characteristics. A total of 877 patients with gastric cancer met the aforementioned criteria and were analyzed in the current study. The clinicopathological characteristics are presented in Table II. The number of patients $\leq 60$ and $>60$ years of age was 459 and 418 , respectively. There were 605 male patients and 272 female patients. A total of 275 (31.4\%) patients received postoperative chemotherapy. The majority of patients were in an advanced stage, with T3 and T4 patients accounting for 48.2 and $25.3 \%$, respectively, and $\mathrm{T} 1$ and $\mathrm{T} 2$ patients accounting for 10.4 and $16.1 \%$, respectively.

Analysis of prognostic factors and survival. As presented in Table III, risk factors were evaluated using univariate and multivariate analyses. Prognostic factors included age, sex, tumor location, tumor size, tumor differentiation, $\mathrm{pT}$ stage, $\mathrm{pN}$ stage, TNM stage, MLR and LODDS. Overall survival rates were shown for patients in different $\mathrm{T}$ subgroups (Fig. 2), N subgroups (Fig. 3), TNM subgroups (Fig. 4), MLR subgroups (Fig. 5) and LODDS subgroups (Fig. 6). Based on univariate analysis, $\mathrm{pT}$ stage, $\mathrm{pN}$ stage, tumor size, tumor differentiation, MLR, LODDS and TNM were identified as significant prognostic risk factors for gastric cancer. However, based on multivariate analysis, tumor size and pT stage were not identified as significant prognostic factors.

Comparison of prognostic value among the three systems. The $\mathrm{C}$-index was used to compare the prognostic discrimination of the three staging systems. As demonstrated in Table IV, when all patients were included ( $\mathrm{LN} \geq 0)$, the $\mathrm{C}$-index of the LODDS staging system was significantly higher compared 
Table I. Overall survival rates according to the value of LODDS with an interval of 0.5 .

\begin{tabular}{lccr}
\hline $\begin{array}{l}\text { LODDS } \\
\text { value }\end{array}$ & $\begin{array}{c}\text { No. of } \\
\text { patients }\end{array}$ & $\begin{array}{c}\text { 5-year OS } \\
\text { rate, } \%\end{array}$ & ap-value \\
\hline LODDS $\leq-1.5$ & 76 & 89.5 & 0.364 \\
$-1.5<\mathrm{LODDS} \leq-1.0$ & 101 & 86.1 & 0.335 \\
$-1.0<\mathrm{LODDS} \leq-0.5$ & 84 & 78.6 & 0.003 \\
$-0.5<\mathrm{LODDS} \leq 0$ & 160 & 59.4 & $<0.001$ \\
$0<\mathrm{LODDS} \leq 0.5$ & 312 & 38.8 & 0.001 \\
$0.5<\mathrm{LODDS} \leq 1.0$ & 62 & 9.7 & $<0.001$ \\
$1.0<\mathrm{LODDS} \leq 1.5$ & 36 & 11.1 & 0.298 \\
$\mathrm{LODDS}>1.5$ & 46 & 8.7 & \\
\end{tabular}

LODDS, $\log$ odds of positive nodes; OS, overall survival. ${ }^{\text {aC Compared }}$ between adjacent subgroups (e.g., a subgroup row and its following subgroup row in the table).

Table II. Clinicopathological characteristics of 877 patients with gastric cancer.

\begin{tabular}{|c|c|}
\hline Characteristic & No. $(\%)$ \\
\hline \multicolumn{2}{|l|}{ Age, years } \\
\hline$\leq 60$ & $459(52.3)$ \\
\hline$>60$ & $418(47.7)$ \\
\hline \multicolumn{2}{|l|}{ Sex } \\
\hline Male & $605(69.0)$ \\
\hline Female & $272(31.0)$ \\
\hline \multicolumn{2}{|l|}{ Tumor location } \\
\hline Upper & $179(20.4)$ \\
\hline Middle & $137(15.6)$ \\
\hline Lower & $550(62.7)$ \\
\hline Entire & $11(1.3)$ \\
\hline \multicolumn{2}{|l|}{ Tumor size, $\mathrm{cm}$} \\
\hline$\leq 5$ & $568(64.8)$ \\
\hline$>5$ & $309(35.2)$ \\
\hline \multicolumn{2}{|c|}{ Tumor differentiation } \\
\hline Well & $44(5.0)$ \\
\hline Moderately & $317(36.1)$ \\
\hline Poorly & $498(56.8)$ \\
\hline Undifferentiated & $18(2.1)$ \\
\hline \multicolumn{2}{|l|}{ pT stage } \\
\hline $\mathrm{T} 1$ & $91(10.4)$ \\
\hline $\mathrm{T} 2$ & $141(16.1)$ \\
\hline $\mathrm{T} 3$ & $423(48.2)$ \\
\hline $\mathrm{T} 4 \mathrm{a}$ & $211(24.1)$ \\
\hline $\mathrm{T} 4 \mathrm{~b}$ & $11(1.3)$ \\
\hline \multicolumn{2}{|l|}{ pN stage } \\
\hline N0 & $223(25.4)$ \\
\hline N1 & $175(20.0)$ \\
\hline $\mathrm{N} 2$ & $265(30.2)$ \\
\hline N3a & $146(16.6)$ \\
\hline $\mathrm{N} 3 \mathrm{~b}$ & $68(7.8)$ \\
\hline
\end{tabular}

Table II. Continued.

\begin{tabular}{|c|c|}
\hline Characteristic & No. $(\%)$ \\
\hline \multicolumn{2}{|l|}{ TNM stage } \\
\hline I & $126(14.4)$ \\
\hline II & $327(37.3)$ \\
\hline IIIA & $183(20.9)$ \\
\hline IIIB & $175(20.0)$ \\
\hline IIIC & $66(7.5)$ \\
\hline \multicolumn{2}{|l|}{ MLR } \\
\hline MLR0 & $223(25.4)$ \\
\hline MLR1 & $203(23.1)$ \\
\hline MLR2 & $451(51.4)$ \\
\hline \multicolumn{2}{|l|}{ LODDS } \\
\hline LODDS 1 & $261(29.8)$ \\
\hline LODDS2 & $160(18.2)$ \\
\hline LODDS3 & $312(35.6)$ \\
\hline LODDS4 & $144(16.4)$ \\
\hline \multicolumn{2}{|c|}{ Number of LN retrieved } \\
\hline$<15$ & $404(46.1)$ \\
\hline$\geq 15$ & $473(53.9)$ \\
\hline \multicolumn{2}{|c|}{ Postoperative chemotherapy } \\
\hline Yes & $275(31.4)$ \\
\hline No & $602(68.6)$ \\
\hline
\end{tabular}

with the $\mathrm{C}$-indexes of the MLR and $\mathrm{pN}$ staging systems $(\mathrm{C}$-index $=0.795,0.790$ and 0.779 , respectively; $\mathrm{P}<0.001)$. The patients were divided into two groups according to the number of LNs retrieved. When the number of retrieved LNs was $<15$, the C-index of the LODDS staging system was significantly higher compared with that of the MLR and $\mathrm{pN}$ staging systems (C-index $=0.792,0.781$ and 0.790, respectively; $\mathrm{P}<0.001$ ). However, when the number of retrieved LNs was $\geq 15$, the C-index of the MLR was significantly higher compared with the LODDS and $\mathrm{pN}$ staging systems $(\mathrm{C}$-index $=0.772,0.780$ and 0.698 , respectively; $\mathrm{P}=0.001$ ).

\section{Discussion}

The TNM system is widely used to offer guidance for the treatment of gastric cancer (7). The 8th edition of the TNM staging system for gastric cancer was released in 2016, replacing the 20097 th edition (8). Compared with the previous edition, the 8 th edition has no changes in the definition of $\mathrm{T}$ and $\mathrm{N}$ classifications. A noteworthy difference in the 8th edition system involves separate consideration of $\mathrm{N} 3 \mathrm{a}$ and N3b in the TNM staging system, which has been demonstrated to achieve improved prognosis prediction in patients with stage III gastric cancer $(5,6)$. A number of previous studies have indicated that the MLR is an improved method for evaluating the prognosis of patients with 
Table III. Univariate and multivariate analyses of prognostic factors.

\begin{tabular}{|c|c|c|c|c|c|c|}
\hline \multirow[b]{2}{*}{ Parameter } & \multirow[b]{2}{*}{ No. of patients } & \multirow[b]{2}{*}{5 -year OS rate, $\%$} & \multirow{2}{*}{$\begin{array}{c}\text { Univariate } \\
\text { analysis } \\
\text { P-value }\end{array}$} & \multicolumn{3}{|c|}{ Multivariate analysis } \\
\hline & & & & HR & $95 \% \mathrm{CI}$ & P-value \\
\hline Age, years & & & 0.677 & & & \\
\hline$\leq 60$ & 459 & 56.2 & & & & \\
\hline$>60$ & 418 & 46.2 & & & & \\
\hline Sex & & & 0.51 & & & \\
\hline Male & 605 & 50.9 & & & & \\
\hline Female & 272 & 52.6 & & & & \\
\hline Tumor location & & & 0.374 & & & \\
\hline Upper & 179 & 52 & & & & \\
\hline Middle & 137 & 51.8 & & & & \\
\hline Lower & 550 & 51.6 & & & & \\
\hline Entire & 11 & 27.3 & & & & \\
\hline Tumor size, $\mathrm{cm}$ & & & 0.001 & 1.983 & $0.942-3.011$ & 0.094 \\
\hline$\leq 5$ & 568 & 61.3 & & & & \\
\hline$>5$ & 309 & 33.3 & & & & \\
\hline Tumor differentiation & & & 0.003 & 1.335 & $1.022-1.844$ & 0.029 \\
\hline Well & 44 & 72.7 & & & & \\
\hline Moderately & 317 & 59 & & & & \\
\hline Poorly & 498 & 46 & & & & \\
\hline Undifferentiated & 18 & 16.7 & & & & \\
\hline pT stage & & & 0.039 & 1.892 & $0.933-2.984$ & 0.556 \\
\hline $\mathrm{T} 1$ & 91 & 84.6 & & & & \\
\hline $\mathrm{T} 2$ & 141 & 72.3 & & & & \\
\hline $\mathrm{T} 3$ & 423 & 44.7 & & & & \\
\hline $\mathrm{T} 4$ & 222 & 37.4 & & & & \\
\hline pN stage & & & $<0.001$ & 2.012 & $1.113-2.868$ & $<0.001$ \\
\hline NO & 223 & 80.3 & & & & \\
\hline $\mathrm{N} 1$ & 175 & 64.6 & & & & \\
\hline $\mathrm{N} 2$ & 265 & 38.9 & & & & \\
\hline N3a & 146 & 28.1 & & & & \\
\hline $\mathrm{N} 3 \mathrm{~b}$ & 68 & 22.1 & & & & \\
\hline TNM stage & & & $<0.001$ & 2.343 & $1.572-3.125$ & 0.006 \\
\hline II & 126 & 87.3 & & & & \\
\hline III & 327 & 60.2 & & & & \\
\hline IV & 424 & 34 & & & & \\
\hline MLR & & & $<0.001$ & 1.766 & $1.023-2.318$ & $<0.001$ \\
\hline MLR0 & 223 & 80.2 & & & & \\
\hline MLR1 & 203 & 62.1 & & & & \\
\hline MLR2 & 451 & 32.6 & & & & \\
\hline LODDS & & & $<0.001$ & 1.875 & $1.101-2.877$ & $<0.001$ \\
\hline LODDS1 & 261 & 84.7 & & & & \\
\hline LODDS2 & 160 & 59.4 & & & & \\
\hline LODDS3 & 312 & 38.8 & & & & \\
\hline LODDS4 & 144 & 9.7 & & & & \\
\hline
\end{tabular}

MLR, metastatic lymph node ratio; LODDS, log odds of positive nodes; OS, overall survival; HR, hazard ratio; CI, confidence interval; pT, tumor depth; pN, pathological node.

gastric cancer compared with the previous TNM staging system $(18,19)$. In addition, the LODDS staging system has been demonstrated to be superior in terms of accuracy compared with the MLR and TNM systems with regard to 


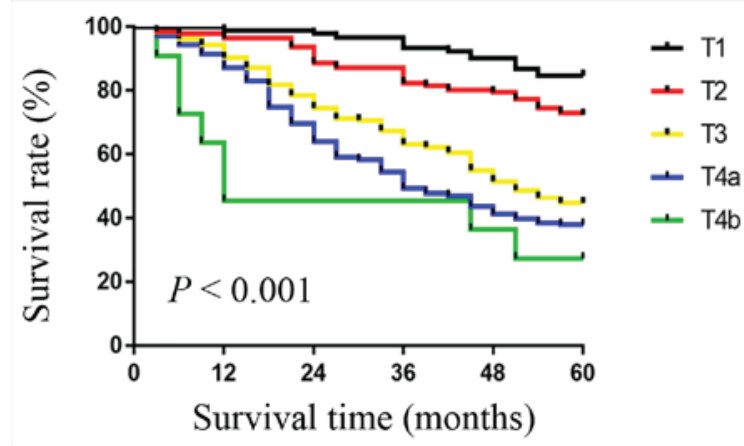

Figure 2. Overall survival rates for patients in different $\mathrm{T}$ subgroups. According to mixed analysis of the five groups, the 5-year survival rate was $84.6 \%$ for $\mathrm{T} 1,72.3 \%$ for $\mathrm{T} 2,44.7 \%$ for $\mathrm{T} 3,37.9 \%$ for $\mathrm{T} 4 \mathrm{a}$ and $27.3 \%$ for $\mathrm{T} 4 \mathrm{~b}$. $\mathrm{P}<0.001$. T, tumor depth.

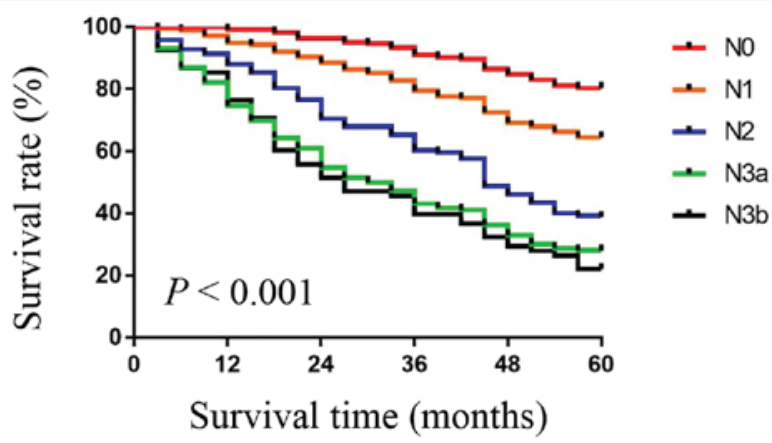

Figure 3. Overall survival rates for patients in different $\mathrm{N}$ subgroups. According to mixed analysis of the five groups, the 5-year survival rate was $80.3 \%$ for N0, $64.6 \%$ for N1, 38.9\% for N2, $28.1 \%$ for N3a and $22.1 \%$ for N3b. $\mathrm{P}<0.001$. N, lymph node.

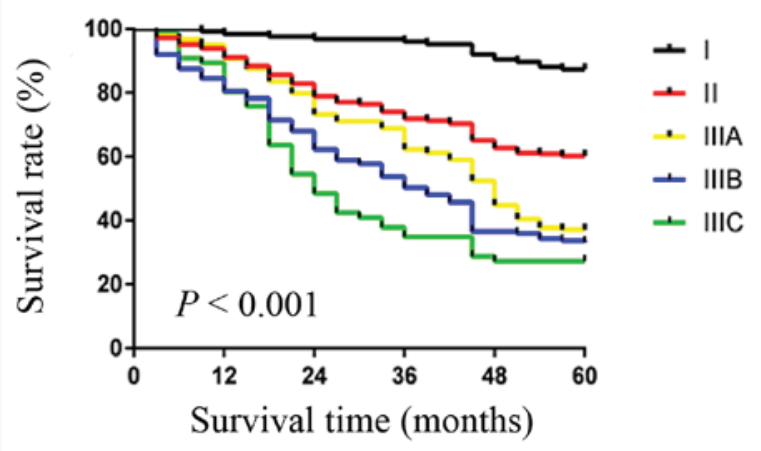

Figure 4. Overall survival rates for patients in different TNM subgroups. According to mixed analysis of the five groups, the 5 -year survival rate was $87.3 \%$ for stage I, $60.2 \%$ for stage II, $37.2 \%$ for stage IIIA, $33.1 \%$ for stage IIIB and $27.3 \%$ for stage IIIC. P<0.001. TNM, tumor-node-metastasis.

predicting survival (20-22). LN stage is considered to be the most important prognostic factor for patients with gastric cancer (14). In addition, clinicopathological characteristics are associated with prognosis (13).

In the current study, the LODDS, MLR and the 8th UICC $\mathrm{pN}$ staging systems were evaluated to compare prognostic prediction. A number of factors were responsible for making the current study novel. Firstly, the 8th UICC pN staging system was considered in the current study, which, to the best

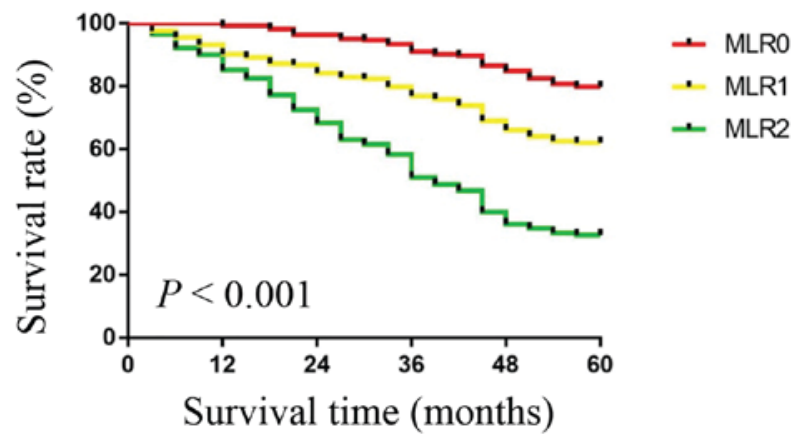

Figure 5. Overall survival rates for patients in different MLR subgroups. According to mixed analysis of the three groups, the 5-year survival rate was $80.2 \%$ for MLR0, $62.1 \%$ for MLR1 and $32.6 \%$ for MLR2. P<0.001. MLR, metastatic lymph node ratio.

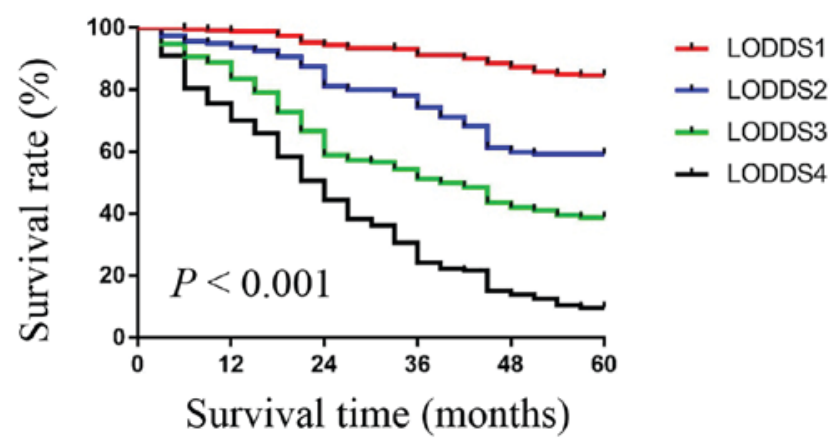

Figure 6. Overall survival rates for patients in different LODDS subgroups. According to mixed analysis of the four groups, the 5-year survival rate was 84.7\% for LODDS1, 59.4\% for LODDS2, 38.8\% for LODDS3 and 9.7\% for LODDS4. $\mathrm{P}<0.001$. LODDS, $\log$ odds of positive nodes.

our knowledge, has not been considered in previous studies. Secondly, the 8th pN, MLR and LODDS staging systems were all compared together while the majority of previous studies have only compared the UICC pN staging system with one other system. Finally, the current study divided the patients into two groups based on the number of retrieved LNs $(<15$ or $\geq 15)$, which may increase the accuracy of determining the best system. The current study concluded that the LODDS staging system is superior to the MLR and TNM staging systems, particularly in patients with $<15$ retrieved LNs.

Based on univariate and multivariate analysis, the MLR, LODDS and pN staging systems were all significantly associated with prognosis. Similar outcomes were identified in a number of previous studies. Jian-Hui et al (16) analyzed 935 patients undergoing radical surgery treatment and demonstrated that the three systems were all independent factors for overall survival based on multivariate analysis. Furthermore, this study concluded that LODDS was the superior staging system. Tóth et al (19) revealed that the LODDS staging system was the best predictor of prognosis when $<16$ LNs were retrieved and the MLR should be applied in patients who underwent extended lymphadenectomies. Aurello et al (23) analyzed 177 patients and identified that the LODDS staging system, nodal ratio and $\mathrm{pN}$ are all prognostic factors based on multivariate analysis, and the LODDS staging system was capable of predicting survival 
Table IV. Comparison of systems in predicting prognosis based on different numbers of retrieved LNs.

\begin{tabular}{|c|c|c|c|c|c|}
\hline No. of LNs retrieved & No. of patients & System & C-index & $95 \% \mathrm{CI}$ & ${ }^{\text {ap}} \mathrm{P}$-value \\
\hline \multirow[t]{3}{*}{$\geq 0$} & 877 & LODDS & 0.795 & $0.568-1.421$ & $<0.001$ \\
\hline & & MLR & 0.790 & $0.512-1.344$ & \\
\hline & & pN staging & 0.779 & $0.606-1.108$ & \\
\hline \multirow[t]{3}{*}{$<15$} & 404 & LODDS & 0.792 & $0.433-1.246$ & $<0.001$ \\
\hline & & MLR & 0.781 & $0.446-1.298$ & \\
\hline & & $\mathrm{pN}$ staging & 0.790 & $0.522-0.998$ & \\
\hline \multirow[t]{3}{*}{$\geq 15$} & 473 & LODDS & 0.772 & $0.502-1.450$ & 0.001 \\
\hline & & MLR & 0.780 & $0.476-0.966$ & \\
\hline & & pN staging & 0.698 & $0.412-0.988$ & \\
\hline
\end{tabular}

MLR, metastatic lymph node ratio; LODDS, log odds of positive nodes; LN, lymph nodes; C-index, Harrell's concordance index; CI, confidence interval; TNM, tumor-node-metastasis. ${ }^{a}$ Compared with the system with the highest $\mathrm{C}$-index.

even when $<15$ LNs were harvested. These studies, in addition to the current study, all supported the hypothesis that LODDS can better minimize stage migration compared with the pN system, particularly when an insufficient number of LNs are retrieved (20).

There is no agreement regarding a cut-off value for MLR in patients with gastric cancer. Zeng et al (24) divided patients into four subgroups and used X-tile to determine the optimal cut-off value. Cut-off values can also be adopted based on commonly used values in previous studies. Tóth et al (19) categorized MLR with four subgroups according to previously published cut-off values. In addition, the median MLR may be used as the cut-off value $(1,2)$. The current study selected the median MLR as the cut-off value and divided the patients into three subgroups. It was identified that patients with high MLRs had low 5-year overall survival rates, as reported by Ke et al (25) in an analysis of 370 patients who underwent R0 surgery. This method of LODDS classification is relatively consistent. The current study stratified LODDS at an interval of 0.5 and compared the overall survival between adjacent subgroups. This method has been adopted by a number of previous studies $(15,19,26,27)$.

The current study compared the C-index of the LODDS, MLR and 8th UICC pN staging systems. The LODDS staging system demonstrated the largest $\mathrm{C}$-index when all patients were included. The same result appeared in the group with $<15 \mathrm{LNs}$ retrieved. In the group with $\geq 15 \mathrm{LNs}$ retrieved, the MLR demonstrated the largest C-index. The results were generally consistent with a study conducted in 2016, in which the LODDS staging system was revealed to be an independent prognostic factor and superior to the MLR and 7th UICC $\mathrm{pN}$ staging systems (15). Aurello et al (23) concluded that the success of the LODDS staging system was not associated with the number of LNs examined and revealed that LODDS could predict survival when $<15$ LNs were retrieved, which was verified by the current study.

In conclusion, the LODDS and MLR staging systems may be adopted as alternative $\mathrm{pN}$ staging systems to predict the prognosis of patients with gastric cancer. Both systems were identified to be superior compared with the 8th edition of the UICC pN staging system. The LODDS staging system exhibits a higher prognostic accuracy compared with MLR when an inadequate number of LNs are retrieved, while MLR is applicable to predict prognosis in cases with adequate lymphadenectomies.

\section{Acknowledgements}

Not applicable.

\section{Funding}

The current study was supported by the Changzhou Municipal Scientific Research grant (grant no. CE20125020).

\section{Availability of data and materials}

The datasets used and/or analyzed during the current study are available from the corresponding author on reasonable request.

\section{Authors' contributions}

$\mathrm{HC}, \mathrm{ZT}$ and YW wrote the manuscript and analyzed clinicopathologic data. ZY, QW, ZL and QL carried out the follow-up and collected the clinicopathologic data of patients. YW assisted $\mathrm{HC}$ and ZT to draft and revise the manuscript, and funded the study. All authors read and approved the final manuscript.

\section{Ethics approval and consent to participate}

The current study was approved by the Ethics Committee of The Third Affiliated Hospital of Soochow University (Changzhou, Jiangsu, China). Informed consent was obtained from all patients.

\section{Patient consent for publication}

Not applicable.

\section{Competing interests}

The authors declare that they have no competing interests. 


\section{References}

1. Attaallah W, Uprak K, Gunal O and Yegen C: prognostic impact of the metastatic lymph node ratio on survival in gastric cancer. Indian J Surg Oncol 7: 67-72, 2016.

2. Taghizadeh-Kermani A, Yahouiyan SZ, AliAkbarian M and Seilanian Toussi M: Prognostic significance of metastatic lymph node ratio in patients with gastric cancer: An evaluation in north-East of iran. Iran J Cancer Prev 7: 73-79, 2014.

3. Kim SG, Seo HS, Lee HH, Song KY and Park CH: Comparison of the differences in survival rates between the 7th and 8th editions of the AJCC tnm staging system for gastric adenocarcinoma: A single-institution study of 5,507 patients in Korea. J Gastric Cancer 17: 212-219, 2017.

4. Marano L,Polom K,Patriti A, Roviello G,Falco G,Stracqualursi A, De Luca R, Petrioli R, Martinotti M, Generali D, et al: Surgical management of advanced gastric cancer: An evolving issue. Eur J Surg Oncol 42: 18-27, 2016.

5. In H, Solsky I, Palis B, Langdon-Embry M, Ajani J and Sano T: Validation of the 8th edition of the AJCC TNM staging system for gastric cancer using the national cancer database. Ann Surg Oncol 24: 3683-3691, 2017.

6. Lu J, Zheng CH, Cao LL, Li P, Xie JW, Wang JB, Lin JX, Chen QY, Lin M and Huang CM: The effectiveness of the 8th American Joint Committee on Cancer TNM classification in the prognosis evaluation of gastric cancer patients: A comparative study between the 7th and 8th editions. Eur J Surg Oncol 43: 2349-2356, 2017.

7. Ji X, Bu ZD, Yan Y, Li ZY, Wu AW, Zhang LH, Zhang J, Wu XJ, Zong XL, Li SX, et al: The 8th edition of the American Joint Committee on Cancer tumor-node-metastasis staging system for gastric cancer is superior to the 7th edition: Results from a Chinese mono-institutional study of 1663 patients. Gastric Cancer 21: 643-652, 2018.

8. Lu J, Zheng CH, Cao LL, Ling SW, Li P, Xie JW, Wang JB, Lin JX, Chen QY, Lin M, et al: Validation of the American Joint Commission on Cancer (8th edition) changes for patients with stage III gastric cancer: Survival analysis of a large series from a Specialized Eastern Center. Cancer Med 6: 2179-2187, 2017.

9. Lee YC, Yang PJ, Zhong Y, Clancy TE, Lin MT and Wang J: Lymph node ratio-based staging system outperforms the seventh AJCC system for gastric cancer: Validation analysis with National Taiwan University Hospital Cancer Registry. Am J Clin Oncol 40: 35-41, 2017.

10. Komatsu S, Ichikawa D, Miyamae M, Kosuga T, Okamoto K, Arita T, Konishi H, Morimura R, Murayama Y, Shiozaki A, et al: Positive lymph node ratio as an indicator of prognosis and local tumor clearance in N3 gastric cancer. J Gastrointest Surg 20: $1565-1571,2016$

11. Liu C, Lu P, Lu Y, Xu H, Wang S and Chen J: Clinical implications of metastatic lymph node ratio in gastric cancer. BMC Cancer 7: 200, 2007.

12. Kunisaki C, Makino H, Akiyama H, Otsuka Y, Ono HA, Kosaka T, Takagawa R, Nagahori Y, Takahashi M, Kito F and Shimada H: Clinical significance of the metastatic lymph-node ratio in early gastric cancer. J Gastrointest Surg 12: 542-549, 2008.

13. Xu DZ, Geng QR, Long ZJ, Zhan YQ, Li W, Zhou ZW, Chen YB, Sun XW, Chen G and Liu Q: Positive lymph node ratio is an independent prognostic factor in gastric cancer after $\mathrm{d} 2$ resection regardless of the examined number of lymph nodes. Ann Surg Oncol 16: 319-326, 2009.
14. Deng J, Liang H, Wang D, Sun D, Ding X, Pan Y and Liu X: Enhancement the prediction of postoperative survival in gastric cancer by combining the negative lymph node count with ratio between positive and examined lymph nodes. Ann Surg Oncol 17: 1043-1051, 2010

15. Lee JW, Ali B, Park CH and Song KY: Different lymph node staging systems in patients with gastric cancer from Korean: What is the best prognostic assessment tool? Medicine (Baltimore) 95: e3860, 2016.

16. Jian-Hui C, Shi-Rong C, Hui W, Si-le C, Jian-Bo X, Er-Tao Z, Chuang-Qi C and Yu-Long H: Prognostic value of three different lymph node staging systems in the survival of patients with gastric cancer following D2 lymphadenectomy. Tumour Biol 37: 11105-11113, 2016.

17. Qiu MZ, Qiu HJ, Wang ZQ, Ren C, Wang DS, Zhang DS, Luo HY, Li YH and Xu RH: The tumor-log odds of positive lymph nodes-metastasis staging system, a promising new staging system for gastric cancer after D2 resection in China. PLoS One 7: e31736, 2012

18. Xu J,Bian YH, Jin X and Cao H: Prognostic assessment of different metastatic lymph node staging methods for gastric cancer after D2 resection. World J Gastroenterol 19: 1975-1983, 2013.

19. Tóth D, Bíró A, Varga Z, Török M and Árkosy P: Comparison of different lymph node staging systems in prognosis of gastric cancer: A bi-institutional study from Hungary. Chin J Cancer Res 29: 323-332, 2017.

20. Spolverato G, Ejaz A, Kim Y, Squires MH, Poultsides G, Fields RC, Bloomston M, Weber SM, Votanopoulos K, Acher AW, et al: Prognostic performance of different lymph node staging systems after curative intent resection for gastric adenocarcinoma. Ann Surg 262: 991-998, 2015.

21. Zhou R, Zhang J, Sun H, Liao Y and Liao W: Comparison of three lymph node classifications for survival prediction in distant metastatic gastric cancer. Int J Surg 35: 165-171, 2016.

22. Calero A, Escrig-Sos J, Mingol F, Arroyo A, Martinez-Ramos D, de Juan M, Salvador-Sanchis JL, Garcia-Granero E, Calpena R and Lacueva FJ: Usefulness of the log odds of positive lymph nodes to predict and discriminate prognosis in gastric carcinomas. J Gastrointest Surg 19: 813-820, 2015.

23. Aurello P, Petrucciani N, Nigri GR, La Torre M, Magistri P, Tierno S, D'Angelo F and Ramacciato G: Log odds of positive lymph nodes (LODDS): What are their role in the prognostic assessment of gastric adenocarcinoma? J Gastrointest Surg 18: 1254-1260, 2014

24. Zeng WJ, Hu WQ, Wang LW, Yan SG, Li JD, Zhao HL, Peng CW, Yang GF and Li Y: Lymph node ratio is a better prognosticator than lymph node status for gastric cancer: A retrospective study of 138 cases. Oncol Lett 6: 1693-1700, 2013.

25. Ke B, Song XN, Liu N, Zhang RP, Wang CL and Liang H: Prognostic value of the lymph node ratio in stage III gastric cancer patients undergoing radical resection. PLoS One 9: e96455, 2014.

26. Sun Z, Xu Y, Li de M, Wang ZN, Zhu GL, Huang BJ, Li K and Xu HM: Log odds of positive lymph nodes: A novel prognostic indicator superior to the number-based and the ratio-based $\mathrm{N}$ category for gastric cancer patients with $\mathrm{R} 0$ resection. Cancer 116 : 2571-2580, 2010.

27. Wang W, Xu DZ, Li YF, Guan YX, Sun XW, Chen YB, Kesari R, Huang CY, Li W, Zhan YQ and Zhou ZW: Tumor-ratio-metastasis staging system as an alternative to the 7th edition UICC TNM system in gastric cancer after D2 resection-results of a single-institution study of 1343 Chinese patients. Ann Oncol 22: 2049-2056, 2011 